Article

\title{
The Effects of Catalyst Support and Temperature on the Hydrotreating of Waste Cooking Oil (WCO) over CoMo Sulfided Catalysts
}

\author{
Hui Wang ${ }^{1,2, *}$, Kyle Rogers ${ }^{2}$, Haiping Zhang ${ }^{2,3}$, Guoliang $\mathrm{Li}^{2}{ }^{2}$, Jianglong Pu ${ }^{1}$, Haoxuan Zheng ${ }^{2}$, \\ Hongfei Lin ${ }^{2}$, Ying Zheng ${ }^{2,4, *}$ and Siauw $\mathrm{Ng}^{5}$ \\ 1 College of Biological, Chemical Sciences and Engineering, Jiaxing University, 118 Jiahang Road, \\ Jiaxing 314001, China \\ 2 Department of Chemical Engineering, University of New Brunswick, 15 Dineen Drive, Fredericton, \\ NB E3B 5A3, Canada \\ 3 Department of Chemical Engineering \& Technology, Tianjin University, Tianjin 300072, China \\ 4 Department of Chemical and Biochemical Engineering, Western University, 1151 Richmond Street, London, \\ ON N6A 3K7, Canada \\ 5 National Centre for Upgrading Technology, Canmet ENERGY-Devon, 1 Oil Patch Drive, Edmonton, \\ AB T9G 1A8, Canada \\ * Correspondence: huiwang@zjxu.edu.cn or hui.wang@unb.ca (H.W.); ying.zheng@uwo.ca (Y.Z.)
}

Received: 25 July 2019; Accepted: 12 August 2019; Published: 15 August 2019

\begin{abstract}
Waste cooking oil (WCO) hydrotreating to produce green diesel is good for both the environmental protection and energy recovery problems. The roles of catalyst support and reaction temperature on reactions during WCO hydrotreating process were evaluated over an unsupported and a commercial sulfided cobalt and molybdenum (CoMoS) catalyst supported by a mixture of $\mathrm{Al}_{2} \mathrm{O}_{3}, \mathrm{TiO}_{2}$, and $\mathrm{SiO}_{2}$. The presence of catalyst support helped to improve the dispersion and enlarge the surface area of CoMoS, and was found to be a key factor in reducing reaction temperature, in enhancing the hydrodeoxygenation (HDO) and hydrogenation capabilities, and in decreasing polymerization capability. The increase of reaction temperature strongly improved the deoxygenation, hydrogenation, and cracking reaction activities. Compared to the unsupported CoMoS, the supported one exhibited good deoxygenation and hydrogenation capabilities at $340{ }^{\circ} \mathrm{C}$ in WCO hydrotreating to produce diesel fraction; however, high temperature operation needs to be carefully controlled because it may cause overcracking and dehydrogenation.
\end{abstract}

Keywords: catalyst support; CoMo sulfided catalyst; deoxygenation; cracking and polymerization; hydrogenation and dehydrogenation; waste cooking oil

\section{Introduction}

Renewable biofuels can reduce greenhouse gas emissions because of the carbon fixation that occurs during plant growth through the process of photosynthesis [1]. The conversion of waste cooking oil (WCO) into fuel is a good method to solve both the environmental protection and energy recovery problems. Biodiesel—fatty acid methyl ester-is the most common biofuel presently; however, it has some drawbacks: (1) high acidic number and low heat value due to the presence of oxygen and (2) air sensitivity due to the presence of unsaturated hydrocarbons. Green diesel, the product from hydrotreating of triglycerides, is made up of deoxygenated and saturated hydrocarbons, and has similar molecular structures to those of petroleum derived diesel fuels. Therefore, hydrotreating is regarded as the potential route to solve all the problems of biodiesel. Another advantage is that the triglyceride-based biofuels can be compatible with the current infrastructure. 
Catalysts are the core for the catalytic reactions, and the reaction routes significantly depend on the catalyst used. $\mathrm{MoS}_{2}$, a very popular catalyst for petroleum hydrodesulfurization and hydrodenitrogenation, and is also regarded as an effective catalyst for deoxygenation during triglyceride hydrotreating [2-8]. The roles of different promoters on the triglyceride deoxygenation process over $\mathrm{MoS}_{2}$ have been extensively investigated. The sulfur vacancies formed when $\mathrm{MoS}_{2}$ was promoted by $\mathrm{Ni}$, which improved the hydrogenation capability and the selectivity of hydrodeoxygenation (HDO) to hydrodecarbonylation/decarboxylation (HDCO) to a higher level. The reason for this improvement is that there is a synergistic effect between $\mathrm{MoS}_{2}$ and $\mathrm{Ni}$ on the unsaturated metal edge sites [9]. Co-promoted $\mathrm{MoS}_{2}$ exhibited saturated edge sites in hydrogen atmosphere, favoring cracking by $\mathrm{C}-\mathrm{C}$ hydrogenolysis, and showed a higher selectivity for HDCO over HDO due to the adsorption of carbon atoms in reactant molecules on the sulfur edge adjacent to Co $[9,10]$.

Different catalyst supports [11], even the same support only differing in morphology, orientation, or composition [12-15], had a significant effect on the hydrotreating process. The dispersion of the metal sulfides and the existence of the bond between metal sulfides and support were influenced by the types of catalyst support; therefore, the activity of deoxygenation and the selectivity of the deoxygenation pathways (HDO and HDCO) could be fine-tuned [16-18]. Alumina-supporting sulfided cobalt and molybdenum (CoMoS) did not correlate with the deoxygenation capability, but it enhanced methylation reactions to a large extent $[10,19]$. Compared to nonacidic support, activated carbon and silica, more acidic CoMoS catalyst supports, such as alumina, enhanced decarbonylation and deesterification reactions of carboxyl groups [16]. Comparing $\mathrm{NiMo} / \mathrm{SAPO}-11$ and $\mathrm{NiMo} / \mathrm{Al}_{2} \mathrm{O}_{3}$, the former had higher selectivity for decarboxylation (41.2\%); whereas the latter favored to hydrodeoxygenation (62.5\%) [20]. Among $\mathrm{SiO}_{2}, \mathrm{Al}_{2} \mathrm{O}_{3}$, and $\mathrm{TiO}_{2}, \mathrm{NiMo} / \mathrm{SiO}_{2}$ showed lower hydrogenation and higher decarboxylation; whereas $\mathrm{NiMo} / \mathrm{TiO}_{2}$ resulted in higher $\mathrm{HDO}$ selectivity [17]. The $\mathrm{Si} /(\mathrm{Si}+\mathrm{Al})$ ratio of catalyst support significantly affected the total acidic sites of catalyst, further changed the deoxygenation reaction rates and pathways [21]. Due to these conflicting results and the lack of studies to discuss non-deoxygenation reactions took place at the same time during WCO hydrotreatment, it is necessary to investigate the roles of catalyst support on triglyceride hydrotreating.

Comparing an unsupported catalyst to a supported catalyst may make it easier to comprehend what role catalyst support plays during WCO deoxygenation process. Besides, operational temperature was found to be the most dominant factor affecting the triglyceride hydrotreating process, which significantly affected product composition [1,22-24]. The previous publications have proven that CoMoS catalysts were efficient deoxygenation catalyst for triglycerides [6-10,12,15,16,19,22]. Moreover, CoMoS catalysts are widely used in petroleum or its fraction hydrotreatment processes; therefore, they are more easily applied in industrial plant. This present work investigated the roles of catalyst support on WCO hydrotreating process by three categories reactions: deoxygenation, hydrogenation/dehydrogenation, and cracking/polymerization by comparing an unsupported CoMoS catalyst and a supported $\left(\mathrm{Al}_{2} \mathrm{O}_{3}-\mathrm{TiO}_{2}-\mathrm{SiO}_{2}\right) \mathrm{CoMoS}$ catalyst at different reaction temperatures. The main objectives were to explore the reaction routes, to identify the effects of support/temperature on product distributions and compositions, and to provide a basis for industrial production using the triglyceride hydrotreating process.

\section{Results and Discussion}

\subsection{Catalyst Characterization}

\subsubsection{Catalyst Morphology and Basic Properties}

The morphology of the unsupported and supported CoMoS catalyst were identified by TEM images (Figure 1). The unsupported CoMoS (Figure 1a) appears to have longer slabs (Figure 1b) than the supported CoMoS. 


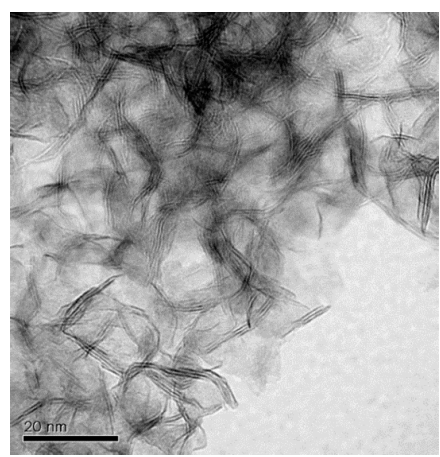

(a)

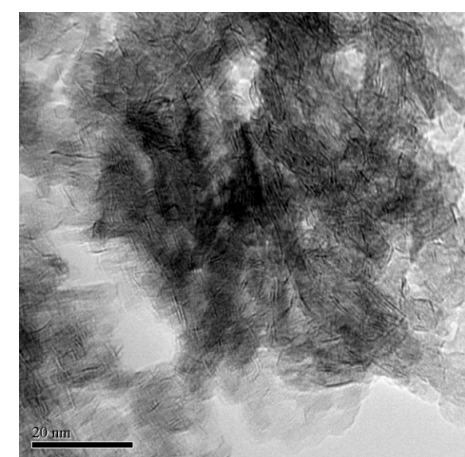

(b)

Figure 1. TEM images of unsupported and supported CoMoS catalysts. (a) Unsupported catalyst and (b) supported catalyst.

The basic properties of the studied CoMoS are shown in Table 1. Regarding the average layer number, the unsupported and supported CoMoS have average layer numbers of 2.9 and 2.3, respectively, and the slab length of the unsupported and supported catalysts was $7.8 \mathrm{~nm}$ and $5.8 \mathrm{~nm}$. Using the method described by Calais et al. [25], the ratios of edge metal atoms to edge atoms (including Co and Mo metal atoms and sulfur atoms) on the unsupported and supported CoMoS catalyst were 0.31 and 0.25 , respectively. This illustrated that the supported CoMoS had more edge metal sites whereas the unsupported one had more saturated sulfur sites. The atomic ratios of Co to the total metal atoms $(\mathrm{Co}+\mathrm{Mo})$ for the unsupported and supported CoMoS were 0.25 and 0.31 , respectively. Compare to the unsupported CoMoS, the supported one had a larger surface area but a smaller pore volume. Figure $\mathrm{S} 1$ shows that the unsupported catalyst has a bimodal pore size distribution: a sharp peak at $2.5 \mathrm{~nm}$ and a broad peak nearby $12 \mathrm{~nm}$; however, only one broad peak near to $6 \mathrm{~nm}$ showed in the supported catalyst pore size distribution results.

Table 1. Basic properties of unsupported and supported CoMoS catalysts.

\begin{tabular}{ccc}
\hline Catalysts & Supported Catalyst & Unsupported Catalyst \\
\hline Average slab length $(\mathrm{nm})$ & 5.84 & 7.80 \\
Average layer numbers & 2.34 & 2.92 \\
Fraction of edge metal atoms & 0.25 & 0.15 \\
Surface area $\left(\mathrm{m}^{2} \mathrm{~g}^{-1}\right)$ & 150.0 & 82.2 \\
Pore volume $\left(\mathrm{cm}^{3} \mathrm{~g}^{-1}\right)$ & 0.35 & 0.53 \\
Co/Mo $(\mathrm{wt} \% / \mathrm{wt} \%)$ & $3.0-4.0 / 16-20$ & $10.3 / 50.4$ \\
$\mathrm{Co} /(\mathrm{Co}+\mathrm{Mo})($ atom ratio) & 0.31 & 0.25 \\
\hline
\end{tabular}

\subsubsection{Active Site Distribution}

The temperature-programmed reduction (TPR) spectra shown in Figure 2 are quantitatively summarized in Table S1.

As can be seen in Figure 2, $\mathrm{H}_{2} \mathrm{~S}$ was not generated over the unsupported catalyst until the temperature was higher than $400{ }^{\circ} \mathrm{C}$. The trials with the supported catalyst generated different results: $\mathrm{H}_{2} \mathrm{~S}$ was detected right when the consumption of $\mathrm{H}_{2}$ began. The temperature of the first $\mathrm{H}_{2}$ consumption peak over the supported catalyst (at 175 to $275^{\circ} \mathrm{C}$ ) was much lower than that over the unsupported catalyst (at approximately 230 to $430{ }^{\circ} \mathrm{C}$ ). This may be explained by: (1) the well dispersion of the active sites by the supports where smaller particles were formed; (2) the presence of catalyst support that limits the growth of $\mathrm{MoS}_{2}$ crystals. These small-sized active phases should show more activity towards the hydrogen reduction and sulfiding since much more contact surfaces are available than the large-sized bulk one (unsupported catalyst). This means that hydrogen could be better dissociatively adsorbed on the active phase for the supported CoMoS catalyst, while much less available hydrogen would participate in the hydrogenation reactions for the unsupported one. 
On the other hand, according to the previous study, the nano-sized metals, such as bare nickel nano particles, are easily agglomerated during a reduction process [26]. This might be the reason that the unsupported catalysts could be easily sintered during the reaction which increases the difficulty of hydrogen reduction and decreases the catalytic activity. As shown in Table S1, the amounts of $\mathrm{H}_{2}$ consumption and $\mathrm{H}_{2} \mathrm{~S}$ production were also much lower over the supported catalyst than over the unsupported catalyst. This is because for the same amount of catalysts, more portions of active phases are contained in the unsupported catalyst than the supported CoMoS catalyst. However, the supported catalyst displayed a higher activity under low reaction temperature $\left(250-275{ }^{\circ} \mathrm{C}\right)$ due to the lower hydrogen reaction temperature of the supported CoMoS (Figure 2). Furthermore, under hydrotreating a temperature range of 250 to $375^{\circ} \mathrm{C}$, unsaturated sulfur vacancies, formed after $\mathrm{H}_{2} \mathrm{~S}$ is produced, are the primary active sites that the supported CoMoS have. Comparatively, saturated sulfurs are the main active sites that the unsupported CoMoS have, because there is no $\mathrm{H}_{2} \mathrm{~S}$ release, which means the consumed hydrogen was adsorbed on saturated sulfur sites. These results that the types of active sites on catalyst surface are in accordance with the fraction of edge metal atoms.

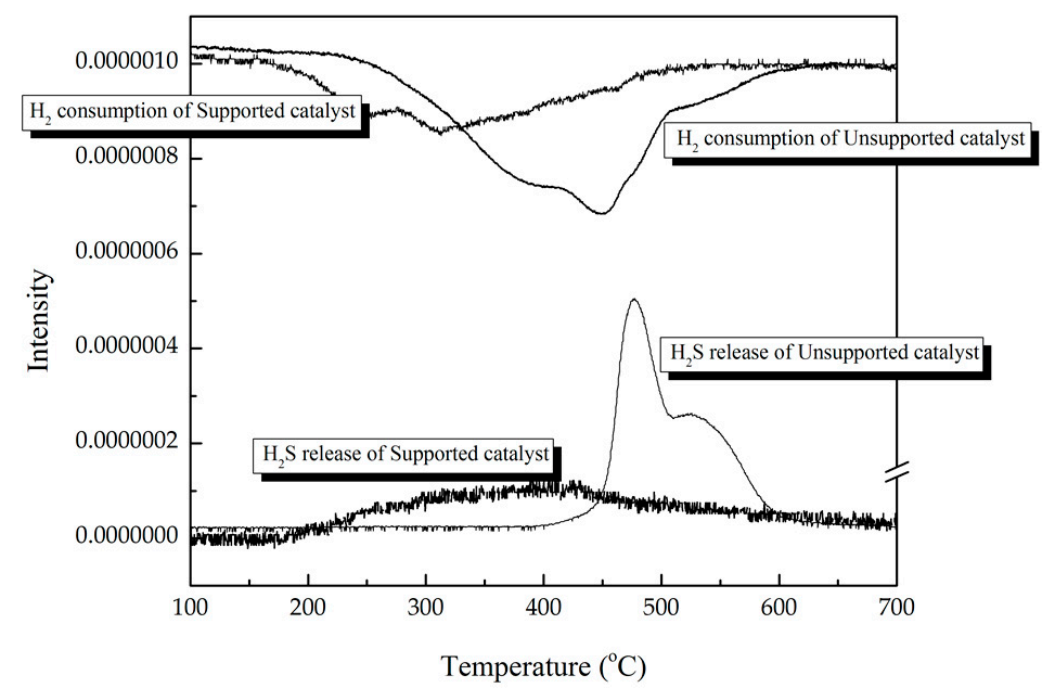

Figure 2. Temperature-programmed reduction (TPR) spectra of the supported and unsupported catalyst.

The unsupported catalyst only contained metal active sites, whereas the supported catalyst was a bifunctional catalyst, having both metal active sites and acidic sites present on the support. There were no strong acids on the catalyst support, while the amounts of weak and medium acids were 2.26 and $0.23 \mathrm{mmol}$ per gram of catalyst. It should be noted that only Lewis acids exist on the support made of alumina and titania. It was reported that the Lewis acids derived from the $\mathrm{Mo}^{4+}$ helped the hydrodeoxygenation process owing to the electron acceptors on the Lewis acid sites where the carbonyl group $(\mathrm{C}=\mathrm{O})$ could be easily adsorbed [27]. Therefore, the comparatively sufficient reduction of the supported CoMoS catalyst leads to the formation of more $\mathrm{Mo}^{4+}$, which are favorable for the hydrodexoygenation, and on the other hand, the Lewis acids on the support also favors to enhance the hydrodexoygenation in the hydrotreating process. This explains the better catalytic performances of the supported CoMoS than that of the unsupported one.

\subsection{Liquid Products}

Compositions of Feed and Liquid Products

The WCO feed was filtered before use. The $\mathrm{H}_{2} \mathrm{O}$ content, density, and total acid value were $0 \%$, $0.9177 \mathrm{~g} / \mathrm{cm}^{3}$, and $0.86 \mathrm{mg} \mathrm{KOH} / \mathrm{g}$, respectively. The feed was primarily composed of triglycerides, which were converted into the corresponding fatty acid methyl esters (determined by GC/MS) [28]. C16 saturated fatty acid (palmitic acid) and C18 unsaturated acids were the primary fatty acids in 
WCO, accounting for $6.7 \pm 0.8 \%$ and $89.3 \pm 0.8 \%(72.4 \pm 1.1 \mathrm{wt} \%$ of oleic acid and $17.5 \pm 0.3 \mathrm{wt} \%$ of linoleic acid), respectively. Figure 3 shows the product fractions of chemical compounds in the hydrotreated liquid products.

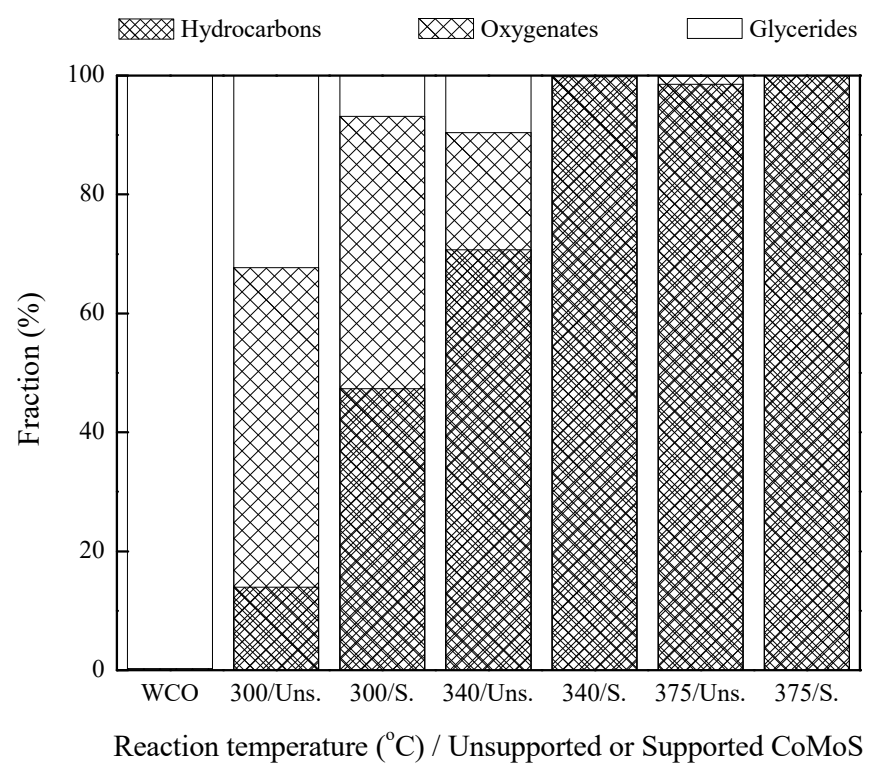

Figure 3. Fraction distribution of liquid products hydrotreated by unsupported and supported CoMoS catalysts. * The number is reaction temperature; Uns and $\mathrm{S}$ mean unsupported and supported CoMoS, respectively. e.g., 340-S: the liquid products are upgraded at $340{ }^{\circ} \mathrm{C}$ over supported CoMoS. The same abbreviations are used in the remaining Figures.

Over the unsupported catalyst, the hydrocarbon fractions increased when the temperature rose from 300 to $375^{\circ} \mathrm{C}$. Over the supported catalyst, the hydrocarbon fractions first increased and then subsequently were stable at $100 \%$ when the temperature rose from 300 to 340 and from 340 to $375^{\circ} \mathrm{C}$, respectively. The hydrocarbon fraction was close to $100 \%$ over the unsupported CoMoS when the temperature was at $375^{\circ} \mathrm{C}$, which was higher than $340{ }^{\circ} \mathrm{C}$ over the supported CoMoS. The existence of the catalyst support dramatically reduced the threshold value of reaction temperature: the supported catalyst needed $\sim 35$ degrees less than the unsupported catalyst to reach a similar deoxygenation extent, which is of great application value in industry. The presence of the catalyst support, $\mathrm{Al}_{2} \mathrm{O}_{3}-\mathrm{TiO}_{2}-\mathrm{SiO}_{2}$, strongly enhanced the deoxygenation capabilities of CoMoS.

\section{Reaction Route Discussion}

Considering the significant differences in liquid product compositions that were obtained by doing the reactions with the supported and unsupported catalyst at different temperatures, the reaction routes were primarily examined from three points of interest: deoxygenation $(\mathrm{C}-\mathrm{O}$ cracking or $\mathrm{C}-\mathrm{CO}$ cracking), cracking ( $\mathrm{C}-\mathrm{C}$ cracking)/polymerization ( $\mathrm{C}-\mathrm{C}$ chain growth), and hydrogenation $(\mathrm{C}=\mathrm{C}$ saturation)/dehydrogenation ( $\mathrm{C}-\mathrm{H}$ disassociation). The reaction routes of the hydrotreated $\mathrm{WCO}$ over the unsupported CoMoS were investigated in a previous study [14]. The simplified reaction pathways are shown in Scheme 1.

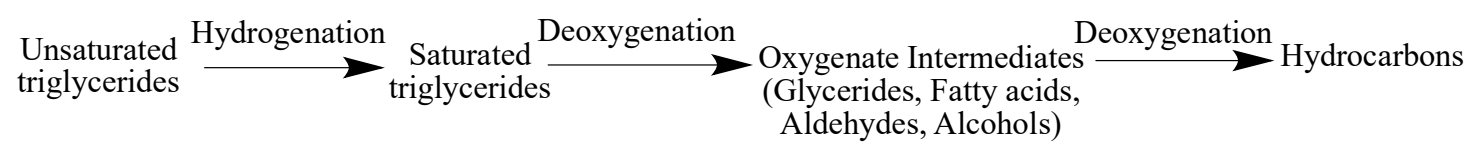

Scheme 1. Simplified reaction pathways during waste cooking oil (WCO) hydrotreating processes.

Unsaturated triglycerides were first subjected to hydrogenation, which transformed unsaturated carbon-carbon double bonds into saturated carbon-carbon single bonds. Oxygen-containing 
intermediates (including glycerides and fatty acids) and gas hydrocarbon products were then produced through the breaking down of the newly saturated triglycerides. This process occurred very quickly and was irreversible [29]. The by-product of this process, glycerol, was quickly converted into propane or propene and water by hydrotreating. The fatty acids were then deoxygenated (through removal of $\mathrm{CO}, \mathrm{CO}_{2}$, or $\mathrm{H}_{2} \mathrm{O}$ ) into hydrocarbons under different reaction routes. The produced hydrocarbons could undergo non-deoxygenate reactions. Focus was placed on the deoxygenation, cracking/polymerization, and hydrogenation/dehydrogenation reactions of the supported and unsupported CoMoS catalyst.

\subsection{Deoxygenation}

\subsubsection{Types of Oxygen Containing Compounds}

The general goal of studying the WCO hydrotreating was to produce oxygen-free diesel fraction.

As shown in Figure 4, the oxygenate fractions in the products decrease with the increase of reaction temperature when using the unsupported $\mathrm{CoMoS}$ as a catalyst. The oxygenates were almost completely removed (less than $0.2 \%$ oxygenates were left) in the products over $340{ }^{\circ} \mathrm{C}$ by using the supported CoMoS; whereas $1.4 \%$ fatty acids existed in the products at $375^{\circ} \mathrm{C}$ by using the unsupported CoMoS. This indicates that the presence of the catalyst support caused an enhancement to the deoxygenation reactions. The oxygenate intermediates in the liquid products by the unsupported and supported CoMoS were primarily fatty acids.

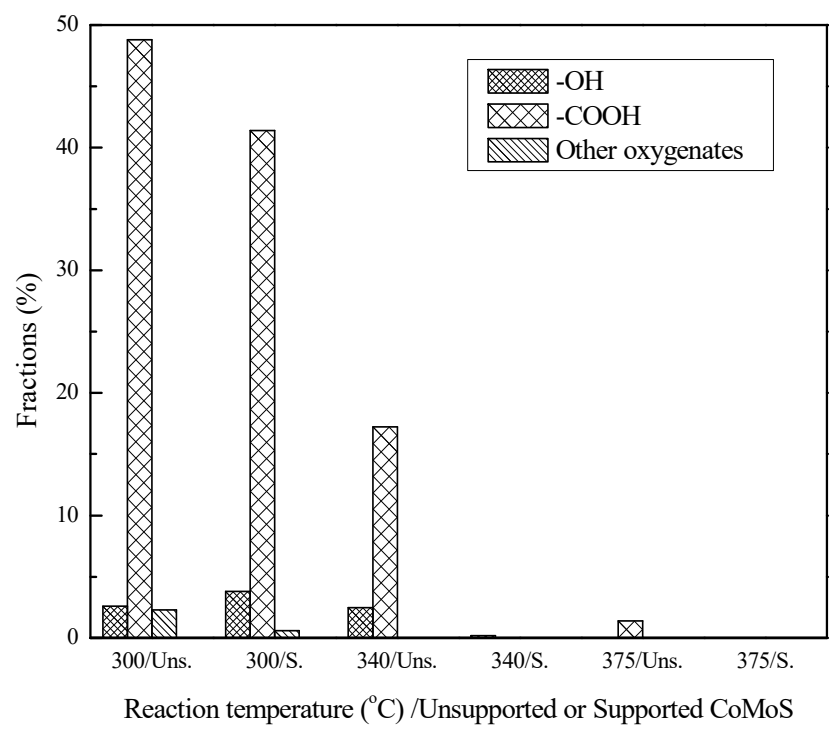

Figure 4. Oxygenates distributions in WCO hydrotreated liquid products.

\subsection{2. $\mathrm{HDO}$ vs. $\mathrm{HDCO}$}

The two reaction routes that fatty acids undergo for deoxygenation are $\mathrm{C}-\mathrm{O}$ cracking (hydrodeoxygenation, $\mathrm{HDO}$ ) and C-CO cracking (HDCO, including hydrodecarbonylation (DCO) and hydrodecarboxylation $\left(\mathrm{DCO}_{2}\right)$ ). Differentiating between $\mathrm{DCO}$ and $\mathrm{DCO}_{2}$ is difficult due to the fact that $\mathrm{CO}$ and $\mathrm{CO}_{2}$ can undergo water-gas shift ( $\mathrm{CO}$ reacting with water to form $\mathrm{H}_{2}$ and $\mathrm{CO}_{2}$ ). From the point of thermodynamics, the methanation of $\mathrm{CO}$ and $\mathrm{CO}_{2}$ becomes possible below $550{ }^{\circ} \mathrm{C}$ and a low temperature is favorable [30,31]. Consequently, under the present reaction conditions $\left(300-375^{\circ} \mathrm{C}\right)$, it is possible that water and methane are produced from the reaction of $\mathrm{CO}$ and/or $\mathrm{CO}_{2}$ to $\mathrm{H}_{2}$ [32]. Therefore, only two deoxygenation routes were considered, HDO and HDCO [33]. Stearic acid was used as an example to illustrate the deoxygenation routes (see Scheme 2). 


$$
\begin{aligned}
& \mathrm{C}_{17} \mathrm{H}_{35} \mathrm{COOH} \stackrel{\text { DCO }\left(-\mathrm{CO},-\mathrm{H}_{2} \mathrm{O}\right)}{\longrightarrow} \mathrm{C}_{17} \mathrm{H}_{34} \stackrel{\text { Hydrogenation }}{\longrightarrow} \mathrm{C}_{17} \mathrm{H}_{36} \\
& \mathrm{C}_{17} \mathrm{H}_{35} \mathrm{COOH} \stackrel{\mathrm{DCO}_{2}\left(-\mathrm{CO}_{2}\right)}{\longrightarrow} \mathrm{C}_{17} \mathrm{H}_{36} \\
& \mathrm{C}_{17} \mathrm{H}_{35} \mathrm{COOH} \stackrel{\mathrm{HDO}\left(+\mathrm{H}_{2},-\mathrm{H}_{2} \mathrm{O}\right)}{\longrightarrow} \mathrm{C}_{17} \mathrm{H}_{35} \mathrm{CHO} \stackrel{\text { Hydrogenation }}{\longrightarrow} \mathrm{C}_{18} \mathrm{H}_{37} \mathrm{OH} \stackrel{\mathrm{HDO}\left(+\mathrm{H}_{2},-\mathrm{H}_{2} \mathrm{O}\right)}{\longrightarrow} \mathrm{C}_{18} \mathrm{H}_{38} \\
& \gamma^{\mathrm{DCO}(-\mathrm{CO})} \\
& \mathrm{C}_{17} \mathrm{H}_{36}
\end{aligned}
$$

(3)

Scheme 2. Deoxygenation routes during WCO hydrotreating processes.

Unsaturated C17 hydrocarbon is produced first due to DCO by releasing CO and water [34], and then C17 olefin can be converted to paraffin (reaction (1) in Scheme 2). The decarboxylation of fatty acid does not require hydrogen and results in saturated $\mathrm{C} 17$ and a by-product of $\mathrm{CO}_{2}$ (reaction (2) in Scheme 2) [35,36], or the saturated C17 (reaction (3) in Scheme 2) is formed from the reduction of fatty acid to aldehyde [37]. $\mathrm{C} 18$ hydrocarbon and by-product, $\mathrm{H}_{2} \mathrm{O}$, are produced through hydrodeoxygenation (reaction (4) in Scheme 2) [38,39], where the alcohol or aldehyde intermediates can be respectively formed from the reduction of aldehydes or fatty acids. The ratio of the occurrences of the HDO reactions to the HDCO reactions can be measured by relating the concentration of even number hydrocarbons to odd number hydrocarbons in the products. Based on the composition of WCO, which consists of a majority of $\mathrm{C} 18$ fatty acids ( $91 \%)$, this method is suitable for obtaining the $\mathrm{HDO} / \mathrm{HDCO}$ ratios. The results were confirmed by the ratios of $\mathrm{C} 16 / \mathrm{C} 15$ because the $\mathrm{C} 16$ content in the WCO is $8.0 \%$ (7.5\% saturated and $0.5 \%$ unsaturated $\mathrm{C} 16)$. The errors were less than $3.0 \%$ between $\mathrm{C} 18 / \mathrm{C} 17$ and $\mathrm{C} 16 / \mathrm{C} 15$ ratios.

The comparison between the C18/C17 ratios of different products is shown in Figure 5.

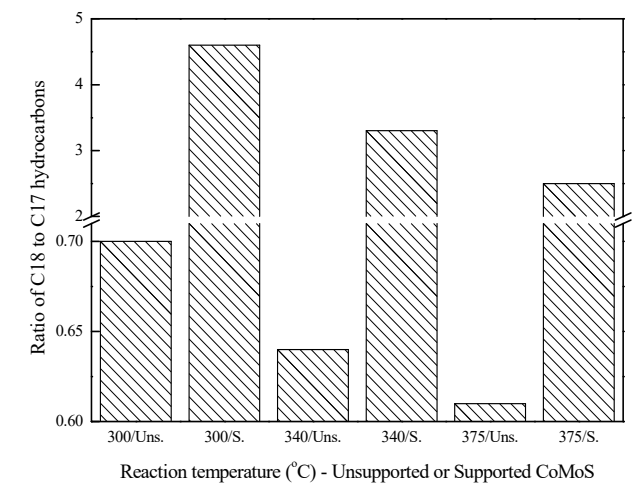

(a)

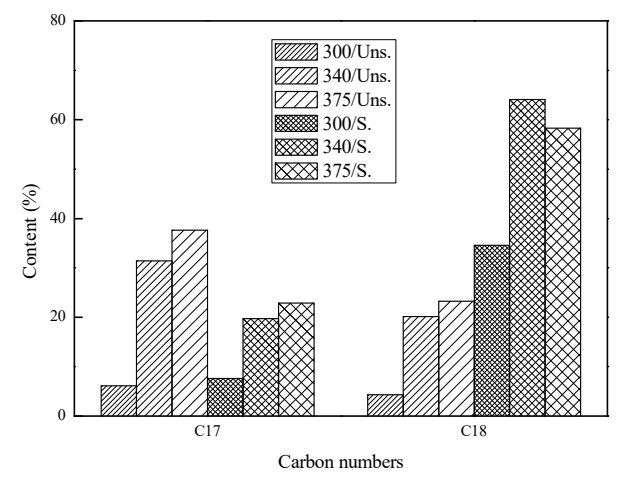

(b)

Figure 5. C17 and C18 distributions in WCO hydrotreated liquid products. (a) Mass ratio of C18/C17 hydrocarbons. (b) C17 and C18 distributions.

It was noticed that the $\mathrm{C} 18 / \mathrm{C} 17$ ratios of the products obtained over the supported CoMoS were much higher than those over the unsupported CoMoS as shown Figure 5. This suggests that HDO was the main reaction pathway of the supported CoMoS catalyst (oxygen was removed primarily in the form of $\mathrm{H}_{2} \mathrm{O}$ ). On the other hand, this result also suggests that $\mathrm{HDCO}$ was the main reaction pathway of the unsupported CoMoS (oxygen was removed primarily in the form of $\mathrm{CO}$ or $\mathrm{CO}_{2}$ ). The presence of the CoMoS catalyst support significantly influenced the triglyceride deoxygenation process, probably because the Lewis acidic sites on the support strengthened the hydrogenolysis capability [16,35], which increased the hydrogen concentration on the catalyst surface, and further 
enhanced the $\mathrm{HDO}$ capability. Lewis acidic sites on the support $\left(\mathrm{Al}_{2} \mathrm{O}_{3}-\mathrm{TiO}_{2}-\mathrm{SiO}_{2}\right)$ might also have increased the occurrence of hydrogenation-dehydration and hydrogenation steps (reactions (3), (6), and (7) in Scheme 2) because the fatty acids bonded with Lewis acidic sites on the catalyst support facilitating the removal of the -OH [35], which led to an enhancement of the HDO pathway.

As shown in Figure 2, the supported catalyst contained abundant sulfur vacancies, whereas the unsupported catalyst contained none until the reaction temperature reached $400^{\circ} \mathrm{C}$. Therefore, at the reaction temperature of 300 to $375{ }^{\circ} \mathrm{C}$, the main active sites of the supported catalyst were sulfur vacancy, whereas the unsupported catalyst was dominated by saturated sites. The distinct active sites are responsible for different main reaction pathways. Combining TPR results and liquid product compositions, the active phases on the supported catalyst have a good ability to dissociate $\mathrm{H}_{2}$ to remove the oxygen by $\mathrm{HDO}$, while the active phases on the unsupported catalyst do not have enough ability to activate the adsorbed hydrogen, resulting in the occurrence of HDCO. In other words, HDO took place on the active sites that were unsaturated and oxygen was removed by the sulfur vacancies residing on the catalyst surface. Conversely, HDCO took place on the sulfur-saturated sites. Ryymin et al observed that reduction reactions (e.g., hydrodeoxygenation and hydrogenation) occurred on unsaturated sites independently and decarbonylation occurred on sulfur-saturated sites when the reactions occurred such as deoxygenation of phenol and methyl heptanoate over a sulphided $\mathrm{NiMo} / \mathrm{Al}_{2} \mathrm{O}_{3}$ catalyst [35]. For both the supported and unsupported CoMoS, the influence of temperature on HDCO was the same: HDCO was found slightly more favorable under higher temperature.

\subsection{Hydrocracking (C-C Cracking) and Polymerization (C-C Chain Growth)}

The cracking and polymerization selectivity of the unsupported and supported CoMoS products at different temperatures were evaluated and the experiment results are shown in Figure 6. WCO was composed of more than $96 \mathrm{wt} \%$ of $\mathrm{C} 16$ and $\mathrm{C} 18$ fatty acids. The $\mathrm{C} 15$ to $\mathrm{C} 18$ hydrocarbons were therefore the expected corresponding deoxygenated products if no cracking and/or polymerization occurred [33]. Hydrocarbons with carbon numbers lower than 15 and carbon numbers higher than 18 were thus considered to be the products of hydrocracking and polymerization, respectively. In comparison with the feed, the hydrotreated products had a higher $\mathrm{C}^{-} 5^{-}$and a lower $\mathrm{C} 15-18$ distribution as shown in Figure 6.

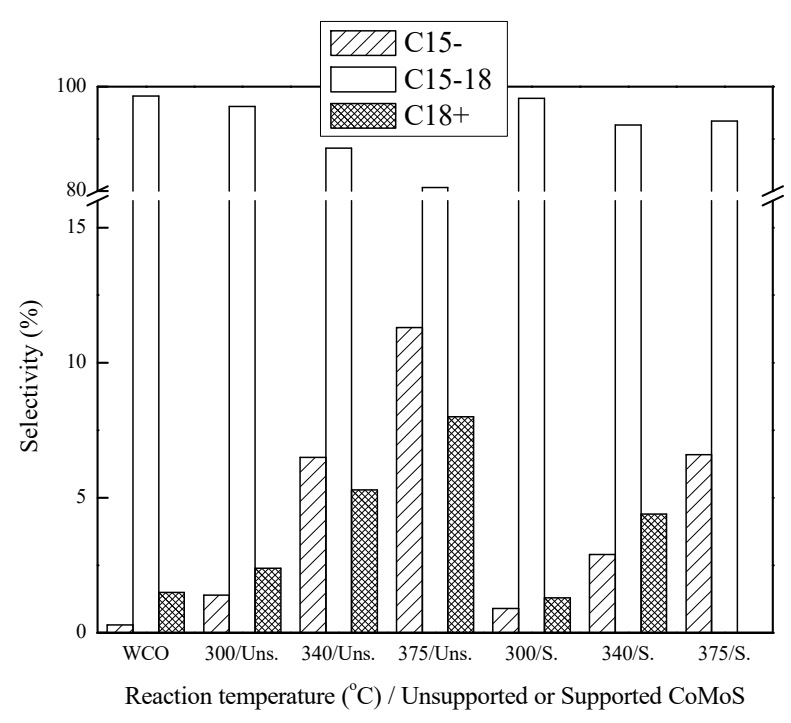

Figure 6. Hydrocracking and polymerization reactions during WCO hydrotreating processes.

All liquid products were primarily composed of C15-18 (over 80\%). Reaction temperature was a key factor in the cracking/polymerization of WCO hydrotreating using a CoMoS catalyst. Bezergianni et al. made the same observation $[1,2,23,40]$. When the reaction temperature increased from 300 to 
$375{ }^{\circ} \mathrm{C}$ over the unsupported CoMoS, the product fraction of hydrocarbons that were lighter than C15 increased from approximately $1.4 \mathrm{wt} \%$ to $11.3 \mathrm{wt} \%$, while C15-18 decreased from $96.2 \mathrm{wt} \%$ to $80.7 \mathrm{wt} \%$. The same effect also occurred for the supported CoMoS: when the reaction temperature increased from 300 to $375{ }^{\circ} \mathrm{C}$, the $\mathrm{C}_{15}$ fraction increased from $0.9 \mathrm{wt} \%$ to $6.6 \mathrm{wt} \%$ and $\mathrm{C} 15-18$ decreased from $97.8 \mathrm{wt} \%$ to $93 \mathrm{wt} \%$.

Over the unsupported $\mathrm{CoMoS}$, the following changes were observed when the reaction temperature increased from 300 to $375{ }^{\circ} \mathrm{C}: 15.5 \mathrm{wt} \%$ of C15-18 was converted into $9.9 \mathrm{wt} \%$ of $\mathrm{C} 15^{-}$and $5.6 \mathrm{wt} \%$ of $\mathrm{C} 8^{+}$. The degree of polymerization increased with increasing reaction temperature. An interesting observation was that at $375{ }^{\circ} \mathrm{C}$ only cracking reactions occurred during WCO hydrotreating over the supported CoMoS-polymerization was not observed. Compared to hydrocarbons with lower carbon number, the higher ones are more reactive during cracking process. Therefore, the disappearance of $\mathrm{C} 18^{+}$hydrocarbons at a high temperature over the supported CoMoS may be explained by the further cracking of the polymerized hydrocarbons into the lighter ones. This is also agreed with the fact that over the supported CoMoS catalyst, the C15-18 hydrocarbons did not undergo a significant decrease from 340 to $375^{\circ} \mathrm{C}$, while the $\mathrm{C} 15^{-}$hydrocarbons increased substantially. On the other hand, a distinct increase in $\mathrm{C} 18^{+}$hydrocarbons was observed from 340 to $375^{\circ} \mathrm{C}$ over the unsupported CoMoS catalyst. This further confirms that the supported CoMoS had higher hydrocracking ability and indicates that Lewis acidic sites on the support $\left(\mathrm{Al}_{2} \mathrm{O}_{3}-\mathrm{TiO}_{2}-\mathrm{SiO}_{2}\right)$ may have an important impact on hydrocracking reaction capabilities.

\subsection{Hydrogenation ( $C=C$ Saturation) and Dehydrogenation ( $C-H$ Disassociation)}

The content of compounds containing $\mathrm{C}=\mathrm{C}$ bonds is important when used as fuels, because olefin content is related to fuel instability. The degree of hydrogenation was revealed by the selectivity of alkanes found in the liquid products, as shown in Figure 7.

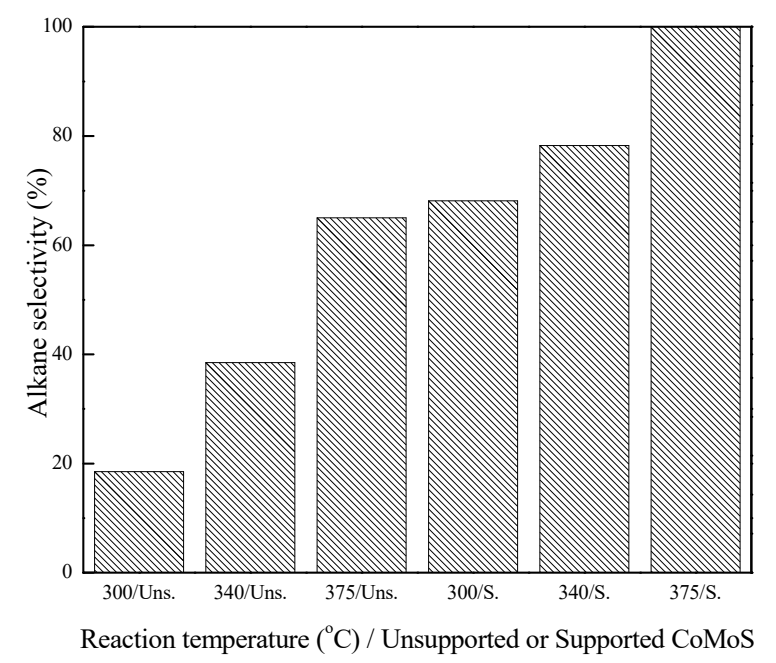

Figure 7. Hydrogenation or dehydrogenation reactions during WCO hydrotreating processes.

According to Figure 7, the alkane selectivity increased with increasing reaction temperature for all trials both over the supported and unsupported catalyst. The majority of oxygenates were removed from the product obtained by upgrading at $375^{\circ} \mathrm{C}$ over the unsupported catalyst; however, there was still a certain amount of unsaturated hydrocarbons (around $35 \mathrm{wt} \%$ ) that were left (shown in Figure 7). When using the supported $\mathrm{CoMoS}$ at $300{ }^{\circ} \mathrm{C}, 340{ }^{\circ} \mathrm{C}$, and $375{ }^{\circ} \mathrm{C}$, more than $68 \mathrm{wt} \%$, $78 \mathrm{wt} \%$, and $100 \mathrm{wt} \%$ hydrocarbons were successfully saturated. This suggests that the supported CoMoS caused a higher hydrogenation activity compared to the unsupported CoMoS. The presence of catalyst support may promote the hydrogenation capabilities [35]. The reason for this is probably because acidic sites on the catalyst support could make the $\mathrm{C}=\mathrm{C}$ bond active, the good dispersion of 
active phases helping to dissociate hydrogen, and could migrate to the $\mathrm{C}=\mathrm{C}$ bonds by spill over to form $\mathrm{C}-\mathrm{C}$ bonds.

Besides, small amount of cyclic hydrocarbons (less than 1.1\%) were found in the liquid products upgraded over both supported and unsupported catalysts when reaction temperature were higher at $375^{\circ} \mathrm{C}$.

The stability of the catalyst is an important part of the research to show the efficiency of the best catalyst; limit to the length of this paper, the authors published the reusability of the supported catalyst under the best condition in the journal of "Molecular Catalysis" [8].

\section{Experimental}

\subsection{Catalyst Preparation and Evaluation}

The synthesis of unsupported catalyst were the same as in the previous studies (using a hydrothermal method with $\mathrm{Na}_{2} \mathrm{~S} \cdot 9 \mathrm{H}_{2} \mathrm{O}, \mathrm{HCl}, \mathrm{MoO}_{3}$, and $\left.\mathrm{Co}\left(\mathrm{NO}_{3}\right)_{2} \cdot 6 \mathrm{H}_{2} \mathrm{O}\right)[9,29]$. The hydrothermal reaction conditions were at $320^{\circ} \mathrm{C}$ for $2 \mathrm{~h}$. The supported CoMoS studied in this work were with a mixture of $\mathrm{Al}_{2} \mathrm{O}_{3}, \mathrm{SiO}_{2}$, and $\mathrm{TiO}_{2}$ as the support and purchased from Liaoning Haitai Sci-Tech Development Co., Ltd. (Fushun, Liaoning, China).

Before evaluation, the catalyst was sulfided at $280{ }^{\circ} \mathrm{C}$ under $1.5 \mathrm{MPa}$ with a flow rate of $80 \mathrm{~mL} / \mathrm{min}$ hydrogen and a $0.1 \mathrm{~mL} \mathrm{~min}^{-1}$ dodecane solution containing $2 \%$ dimethyl disulfide (DMDS) for $2 \mathrm{~h}$. Hydrotreating of WCO was carried out in an autoclave (Parker Autoclave Engineers Inc., Erie, PA, USA, 1L) under a pressure of $9 \mathrm{MPa}$ hydrogen $(99.99 \%)$ and at temperatures of 300,340 , and $375^{\circ} \mathrm{C}$. The mass ratio of catalyst active component to feed was 1:200 and the reaction time was $8 \mathrm{~h}$. A blank testing without catalyst was carried out at $375{ }^{\circ} \mathrm{C}$ and the thermal reaction effect was not considered because of the low glyceride/oxygen conversion [29].

\subsection{Catalyst Characterization}

An Autosorb-1 (ANTON PAAR USA INC., Ashland, VA, USA) was used to test the physical properties of the investigated CoMoS. All detailed testing information is the same as the previous publication $[9,29]$.

An Autosorb-1 combined with a RGA-200 (Stanford Research Systems, Sunnyvale, CA, USA) was used to detect $\mathrm{NH}_{3}$-TPD and TPR, which reveal the amount and strength of active sites on the catalysts, respsectively.

TEM (JEOL 2011, JEOL Ltd., Otemachi, Chiyoda, Tokyo, Japan) was used to determine the morphology of CoMoS, and EDX (Genesis 4000 spectrometer) was used to estimate the elements and their approximate composition in the unsupported CoMoS. The elemental compositions of the supported CoMoS were determined by A JEOL JXA-733 Electron Microprobe analyzer (JEOL Ltd., Otemachi, Chiyoda, Tokyo, Japan). Image analysis software was used to measure the slab length and layer numbers of CoMoS. The average slab length and layer numbers were calculated from $100^{+}$slabs from different particles.

The sulfur content of the unsupported and supported catalyst was detected using an elemental analyzer (CHN-932, LECO Empowering Results, St. Joseph, MI, USA) and an Antek Nitrogen/Sulfur Analyzer (NS-9000, Antek Instruments, Inc., Houston, TX, USA), respectively.

\subsection{Product Analysis}

The qualitative chemical compositions of liquid products were analyzed by a gas chromatograph (Shimadzu GC-17A, Shimadzu Scientific Instruments, Kyoto, Japan) coupled to a mass spectrometer (Shimadzu MS-QP5000) (GC/MS, Shimadzu Scientific Instruments, Kyoto, Japan).

The quantitative testing of hydrocarbons in liquid samples was determined by external standard method using a Varian 450 gas chromatograph (Agilent Technologies, Inc., Santa Clara, CA, USA). 
The quantitative testing of oxygenates was determined as follows. The total oxygen content in the feed and in the liquid products was calculated by the difference of carbon and hydrogen contents that were examined by a CHN-932 elemental analyzer (LECO Empowering Results, St. Joseph, MI, USA) according to ASTM D 5291. The free fatty acids were analyzed by both gas chromatography (Shimadzu GC-17A, Shimadzu Scientific Instruments, Kyoto, Japan) and titration (ZD-2A Automatic potentiometric titrator, Rex, Shanghai, China) according to ASTM D 664. The contents of alcohols and aldehydes were calculated from GC/MS results by the peak area and response factor of 1.3 and 1.4, respectively [41]. The oxygen balance was used to calculate the content of unreacted glycerides.

\subsection{Calculations}

Hydrogenation activity is reflected by alkane selectivity (Equation (1)).

$$
\text { Alkane selectivity }=\frac{\text { Mass of Alkanes }}{\text { Mass of (Alkanes }+ \text { Alkenes })}
$$

All detailed testing information is the same as the previous publication $[9,29,42,43]$.

\section{Conclusions}

This research investigated the roles of the catalyst support and reaction temperature on WCO hydrotreating process by evaluating the deoxygenation, cracking/polymerization, and hydrogenation/dehydrogenation performances of an unsupported CoMoS catalyst and an $\mathrm{Al}_{2} \mathrm{O}_{3}-\mathrm{TiO}_{2}-\mathrm{SiO}_{2}$ supported $\mathrm{CoMoS}$ catalyst.

In the deoxygenation process, the hydrocarbon fraction was close to $100 \mathrm{wt} \%$ in the products that were upgraded at $375^{\circ} \mathrm{C}$ over the unsupported CoMoS and $340^{\circ} \mathrm{C}$ over the supported CoMoS, respectively. HDO was the main reaction pathway of the supported CoMoS catalyst and HDCO was the main reaction pathway of the unsupported CoMoS. The increase in reaction temperature did not affect the main reaction pathways, yet it slightly enhanced HDCO capability.

In the hydrocracking and polymerization process, the unsupported catalyst was correlated with higher levels of polymerization when compared to the supported catalyst because of lack of the acidic support. The increase in reaction temperature enhanced the cracking and polymerization capability for the unsupported catalyst, but only cracking capability for the supported catalyst.

In the hydrogenation and dehydrogenation process, the dehydrogenation reaction occurred when the reaction temperature was above $375^{\circ} \mathrm{C}$. Compared to the unsupported CoMoS, the supported CoMoS exhibited higher hydrogenation capability at $300-375^{\circ} \mathrm{C}$.

During WCO hydrotreating process, the presence of the CoMoS catalyst support enhanced $\mathrm{HDO}$, reduced the polymerization degree, and decreased the reaction temperature. The increase in reaction temperature promoted the deoxygenation, hydrogenation, and cracking reaction capabilities. The supported CoMoS exhibited good deoxygenation and hydrogenation capabilities under $340^{\circ} \mathrm{C}$ in WCO hydrotreating to produce diesel fraction; however, high temperature operation needs to be carefully controlled because it may cause overcracking and dehydrogenation.

Supplementary Materials: The following are available online at http://www.mdpi.com/2073-4344/9/8/689/s1, Figure S1: BJH pore size distribution of the supported and unsupported catalyst, Table S1: The amount of active sites on the supported and unsupported catalyst.

Author Contributions: Conceptualization: H.W., H.Z. (Haiping Zhang), H.L., S.N. and Y.Z.; Data curation: H.W., H.Z. (Haiping Zhang), G.L. and K.R.; Formal analysis: H.W., H.Z. (Haiping Zhang), H.L., G.L. and K.R.; Funding acquisition: Y.Z. and H.W.; Investigation: H.W., H.Z. (Haiping Zhang), G.L., K.R. and H.Z. (Haoxuan Zheng); Methodology: H.W., H.Z. (Haiping Zhang), H.L., S.N. and Y.Z.; Project administration: H.W., H.Z. Haiping Zhang), H.L. and Y.Z.; Resources: Y.Z.; Software: H.W., H.Z. (Haiping Zhang), H.L., G.L. and K.R.; Supervision: H.W. and Y.Z.; Validation: H.W., H.Z. (Haiping Zhang), G.L., K.R. and H.Z. (Haoxuan Zheng); Visualization: H.W., K.R., H.Z. (Haiping Zhang) and Y.Z.; Writing—original draft: H.W., K.R. and H.Z. (Haiping Zhang); Writing一review \& editing: H.W., Y.Z. and J.P. 
Funding: The authors gratefully thank the Natural Sciences and Engineering Research Council of Canada (NSERC strategic: 463140-2014STPGP, NSERC DISCOVERY: RGPIN-2015-03869), the Canada Foundation for Innovation (\#31983), the Canada Research Chairs Program (950-228053), and Jiaxing University (\#70518034) for financial assistance.

Conflicts of Interest: The authors declare no conflict of interest.

\section{Abbreviations}

$\begin{array}{ll}\text { WCO } & \begin{array}{l}\text { waste cooking oil. } \\ \text { solfided Cobalt and Molybdenum. } \\ \text { hydrodeoxygenation. In the HDO reaction, oxygen is removed in the form of water by } \\ \text { adding hydrogen into oxygen-containing compounds. } \\ \text { hydrodecarbonylation and decarboxylation. } \\ \text { the process in the hydrodecarbonylation reaction, in which oxygen is removed in the form } \\ \text { of water and CO. } \\ \text { the process in the hydrodecarboxylation reaction, in which oxygen is removed in the form } \\ \text { of } \mathrm{CO}_{2} .\end{array} \\ \mathrm{DCO}_{2} & \begin{array}{l}\text { a medium-pore silicoaluminophosphate molecular sieve with tunable acidity. } \\ \text { A stands for the active metal of the catalyst, B stands for the support of the catalyst. For } \\ \text { example, CoMoS/SiO }\end{array} \\ \text { A/B catalyst means that the active metal of the catalyst is sulfided Cobalt and } \\ \end{array} \quad \begin{aligned} & \text { Molybdenum, and the support of the catalyst is Silica. }\end{aligned}$

\section{References}

1. Bezergianni, S.; Dimitriadis, A.; Kalogianni, A.; Pilavachi, P.A. Hydrotreating of waste cooking oil for biodiesel production. Part I: Effect of temperature on product yields and heteroatom removal. Bioresour. Technol. 2010, 101, 6651-6656. [CrossRef] [PubMed]

2. Bezergianni, S.; Dimitriadis, A.; Kalogianni, A.; Knudsen, K.G. Toward Hydrotreating of Waste Cooking Oil for Biodiesel Production. Effect of Pressure, $\mathrm{H}_{2} /$ Oil Ratio, and Liquid Hourly Space Velocity. Ind. Eng. Chem. Res. 2011, 50, 3874-3879. [CrossRef]

3. Veriansyah, B.; Han, J.Y.; Kim, S.K.; Hong, S.-A.; Kim, Y.J.; Lim, J.S.; Shu, Y.-W.; Oh, S.-G.; Kim, J. Production of renewable diesel by hydroprocessing of soybean oil: Effect of catalysts. Fuel 2012, 94, 578-585. [CrossRef]

4. Sankaranarayanan, T.M.; Banu, M.; Pandurangan, A.; Sivasanker, S. Hydroprocessing of sunflower oil-gas oil blends over sulfided Ni-Mo-Al-zeolite beta composites. Bioresour. Technol. 2011, 102, 10717-10723. [CrossRef] [PubMed]

5. Guzman, A.; Torres, J.E.; Prada, L.P.; Nuñez, M.L. Hydroprocessing of crude palm oil at pilot plant scale. Catal. Today 2010, 156, 38-43. [CrossRef]

6. Kubička, D.; Šimáček, P.; Žilková, N. Transformation of Vegetable Oils into Hydrocarbons over Mesoporous-Alumina-Supported CoMo Catalysts. Top. Catal. 2009, 52, 161-168. [CrossRef]

7. Wang, H.; Zhang, L.; Li, G.; Rogers, K.; Lin, H.; Seers, P.; Ledan, T.; Ng, S.; Zheng, Y. Application of uniform design experimental method in waste cooking oil (WCO) co-hydroprocessing parameter optimization and reaction route investigation. Fuel 2017, 210, 390-397. [CrossRef]

8. Wang, H.; Li, G.; Rogers, K.; Lin, H.; Zheng, Y.; Ng, S. Hydrotreating of waste cooking oil over supported CoMoS catalyst-Catalyst deactivation mechanism study. Mol. Catal. 2017, 443, 228-240. [CrossRef]

9. Zhang, H.; Lin, H.; Zheng, Y. The role of cobalt and nickel in deoxygenation of vegetable oils. Appl. Catal. B Environ. 2014, 160, 415-422. [CrossRef]

10. Bui, V.N.; Laurenti, D.; Afanasiev, P.; Geantet, C. Hydrodeoxygenation of guaiacol with CoMo catalysts. Part I: Promoting effect of cobalt on HDO selectivity and activity. Appl. Catal. B Environ. 2011, 101, $239-245$. [CrossRef]

11. Shimada, H. Morphology and orientation of $\mathrm{MoS}_{2}$ clusters on $\mathrm{Al}_{2} \mathrm{O}_{3}$ and $\mathrm{TiO}_{2}$ supports and their effect on catalytic performance. Catal. Today 2003, 86, 17-29. [CrossRef]

12. Qiherima; Li, H.; Yuan, H.; Zhang, Y.; Xu, G. Effect of Alumina Support on the Formation of the Active Phase of Selective Hydrodesulfurization Catalysts $\mathrm{Co}-\mathrm{Mo} / \mathrm{Al}_{2} \mathrm{O}_{3}$. Chin. J. Catal. 2011, 32, 240-249. [CrossRef]

13. Sakashita, Y.; Araki, Y.; Shimada, H. Effects of surface orientation of alumina supports on the catalytic functionality of molybdenum sulfide catalysts. Appl. Catal. A Gen. 2001, 215, 101-110. [CrossRef] 
14. Rana, M.S.; Ancheyta, J.; Maity, S.K.; Rayo, P. Maya crude hydrodemetallization and hydrodesulfurization catalysts: An effect of $\mathrm{TiO}_{2}$ incorporation in $\mathrm{Al}_{2} \mathrm{O}_{3}$. Catal. Today 2005, 109, 61-68. [CrossRef]

15. De la Puente, G.; Gil, A.; Pis, J.J.; Grange, P. Effects of Support Surface Chemistry in Hydrodeoxygenation Reactions over CoMo/Activated Carbon Sulfided Catalysts. Langmuir 1999, 15, 5800-5806. [CrossRef]

16. Centeno, A.; Laurent, E.; Delmon, B. Influence of the Support of CoMo Sulfide Catalysts and of the Addition of Potassium and Platinum on the Catalytic Performances for the Hydrodeoxygenation of Carbonyl, Carboxyl, and Guaiacol-Type Molecules. J. Catal. 1995, 154, 288-298. [CrossRef]

17. Kubicka, D.; Horacek, J.; Setnicka, M.; Bulanek, R.; Zukal, A.; Kubickova, I. Effect of support-active phase interactions on the catalyst activity and selectivity in deoxygenation of triglycerides. Appl. Catal. B Environ. 2014, 145, 101-107. [CrossRef]

18. Wang, H.; Yan, S.; Salley, S.; Ng, K. Support effects on hydrotreating of soybean oil over NiMo carbide catalyst. Fuel 2013, 111, 81-87. [CrossRef]

19. Bui, V.N.; Laurenti, D.; Delichère, P.; Geantet, C. Hydrodeoxygenation of guaiacol: Part II: Support effect for CoMoS catalysts on HDO activity and selectivity. Appl. Catal. B Environ. 2011, 101, 246-255. [CrossRef]

20. Chen, H.; Wang, Q.; Zhang, X.; Wang, L. Effect of support on the NiMo phase and its catalytic hydrodeoxygenation of triglycerides. Fuel 2015, 159, 430-435. [CrossRef]

21. Gong, S.; Shinozaki, A.; Qian, W. Role of Support in Hydrotreatment of Jatropha Oil over Sulfided NiMo Catalysts. Ind. Eng. Chem. Res. 2012, 51, 13953-13960. [CrossRef]

22. Krár, M.; Kovács, S.; Kalló, D.; Hancsók, J. Fuel purpose hydrotreating of sunflower oil on $\mathrm{CoMo} / \mathrm{Al}_{2} \mathrm{O}_{3}$ catalyst. Bioresour. Technol. 2010, 101, 9287-9293. [CrossRef] [PubMed]

23. Bezergianni, S.; Dimitriadis, A.; Sfetsas, T.; Kalogianni, A. Hydrotreating of waste cooking oil for biodiesel production. Part II: Effect of temperature on hydrocarbon composition. Bioresour. Technol. 2010, 101, 7658-7660. [CrossRef] [PubMed]

24. Toba, M.; Abe, Y.; Kuramochi, H.; Osako, M.; Mochizuki, T.; Yoshimura, Y. Hydrodeoxygenation of waste vegetable oil over sulfide catalysts. Catal. Today 2011, 164, 533-537. [CrossRef]

25. Calais, C.; Matsubayashi, N.; Geantet, C.; Yoshimura, Y.; Shimada, H.; Nishijima, A.; Lacroix, M.; Breysse, M. Crystallite Size Determination of Highly Dispersed Unsupported $\mathrm{MoS}_{2}$ Catalysts. J. Catal. 1998, 174, 130-141. [CrossRef]

26. Pu, J.; Nishikado, K.; Wang, N.; Nguyen, T.T.; Maki, T.; Qian, E.W. Core-shell nickel catalysts for the steam reforming of acetic acid. Appl. Catal. B Environ. 2018, 224, 69-79. [CrossRef]

27. Chen, N.; Gong, S.; Qian, E.W. Effect of reduction temperature of $\mathrm{NiMoO}_{3-\mathrm{x}} / \mathrm{SAPO}-11$ on its catalytic activity in hydrodeoxygenation of methyl laurate. Appl. Catal. B Environ. 2015, 174, 253-263. [CrossRef]

28. Šimáček, P.; Kubička, D.; Šebor, G.; Pospíšil, M. Hydroprocessed rapeseed oil as a source of hydrocarbon-based biodiesel. Fuel 2009, 88, 456-460. [CrossRef]

29. Zhang, H.; Lin, H.; Wang, W.; Zheng, Y.; Hu, P. Hydroprocessing of waste cooking oil over a dispersed nano catalyst: Kinetics study and temperature effect. Appl. Catal. B Environ. 2014, 150, 238-248. [CrossRef]

30. Pu, J.; Luo, Y.; Wang, N.; Bao, H.; Wang, X.; Qian, E.W. Ceria-promoted $\mathrm{Ni@} \mathrm{Al}_{2} \mathrm{O}_{3}$ core-shell catalyst for steam reforming of acetic acid with enhanced activity and coke resistance. Int. J. Hydrogen Energy 2018, 43, 3142-3153. [CrossRef]

31. Pu, J.; Toyoda, T.; Qian, E.W. Evaluation of Reactivities of Various Compounds in Steam Reforming over $\mathrm{RuNi} / \mathrm{BaOAl}_{2} \mathrm{O}_{3}$ Catalyst. Energy Fuels 2018, 32, 1804-1811. [CrossRef]

32. Donnis, B.; Egeberg, R.G.; Blom, P.; Knudsen, K.G. Hydroprocessing of Bio-Oils and Oxygenates to Hydrocarbons. Understanding the Reaction Routes. Top. Catal. 2009, 52, 229-240.

33. Huber, G.W.; O'Connor, P.; Corma, A. Processing biomass in conventional oil refineries: Production of high quality diesel by hydrotreating vegetable oils in heavy vacuum oil mixtures. Appl. Catal. A Gen. 2007, 329, 120-129. [CrossRef]

34. Gusmão, J.; Brodzki, D.; Djéga-Mariadassou, G.; Frety, R. Utilization of vegetable oils as an alternative source for diesel-type fuel: Hydrocracking on reduced $\mathrm{Ni} / \mathrm{SiO}_{2}$ and sulphided $\mathrm{Ni}-\mathrm{Mo} / \gamma-\mathrm{Al}_{2} \mathrm{O}_{3}$. Catal. Today 1989, 5 , 533-544. [CrossRef]

35. Ryymin, E.-M.; Honkela, M.L.; Viljava, T.-R.; Krause, A.O.I. Competitive reactions and mechanisms in the simultaneous $\mathrm{HDO}$ of phenol and methyl heptanoate over sulphided $\mathrm{NiMo} / \gamma-\mathrm{Al}_{2} \mathrm{O}_{3}$. Appl. Catal. A Gen. 2010, 389, 114-121. [CrossRef] 
36. Brunet, S.; Mey, D.; Pérot, G.; Bouchy, C.; Diehl, F. On the hydrodesulfurization of FCC gasoline: A review. Appl. Catal. A Gen. 2005, 278, 143-172. [CrossRef]

37. Şenol, O.İ.; Ryymin, E.M.; Viljava, T.R.; Krause, A.O.I. Reactions of methyl heptanoate hydrodeoxygenation on sulphided catalysts. J. Mol. Catal. A Chem. 2007, 268, 1-8. [CrossRef]

38. Kubička, D.; Kaluža, L. Deoxygenation of vegetable oils over sulfided Ni, Mo and NiMo catalysts. Appl. Catal. A Gen. 2010, 372, 199-208. [CrossRef]

39. Boda, L.; Onyestyák, G.; Solt, H.; Lónyi, F.; Valyon, J.; Thernesz, A. Catalytic hydroconversion of tricaprylin and caprylic acid as model reaction for biofuel production from triglycerides. Appl. Catal. A Gen. 2010, 374, 158-169. [CrossRef]

40. Bezergianni, S.; Dimitriadis, A. Temperature effect on co-hydroprocessing of heavy gas oil-waste cooking oil mixtures for hybrid diesel production. Fuel 2013, 103, 579-584. [CrossRef]

41. Costa, R.; d'Acampora Zellner, B.; Crupi, M.L.; Fina, M.R.D.; Valentino, M.R.; Dugo, P.; Dugo, G.; Mondello, L. GC-MS, GC-O and enantio-GC investigation of the essential oil of Tarchonanthus camphoratus L. Flavour Fragr. J. 2008, 23, 40-48. [CrossRef]

42. Wang, H.; Lin, H.; Feng, P.; Han, X.; Zheng, Y. Integration of catalytic cracking and hydrotreating technology for triglyceride deoxygenation. Catal. Today 2017, 291, 172-179. [CrossRef]

43. Wang, H.; Lin, H.; Zheng, Y.; Ng, S.; Brown, H.; Xia, Y. Kaolin-based catalyst as a triglyceride FCC upgrading catalyst with high deoxygenation, mild cracking, and low dehydrogenation performances. Catal. Today 2019, 319, 164-171. [CrossRef]

(C) 2019 by the authors. Licensee MDPI, Basel, Switzerland. This article is an open access article distributed under the terms and conditions of the Creative Commons Attribution (CC BY) license (http://creativecommons.org/licenses/by/4.0/). 